\title{
Research on reinforcement of soft soil by geotextile
}

\author{
Qiong Wang ${ }^{1, a}$, Gang Chen ${ }^{2, b}$, Endong Guo ${ }^{3, c}$ \\ ${ }^{1}$ Harbin University, Harbin 150086, China \\ ${ }^{2}$ Heilongjiang Institute of Science and Technology \\ ${ }^{3}$ Institute of Engineering Mechanics, China Earthquake Administration, Harbin 150080 \\ awangqiong1127@163.com, b26915715@qq.com, ciemged@263.net
}

Keywords: geotextile, soft soil, reinforcement, experiment, curve fitting

\begin{abstract}
Because of low shear strength of soft soil, it has harmful characters in actual engineering. Compound material, composed of geotextile and sand and gravel, is used to reinforce soft soil, because of advantage of good tensile compressive stress. The reinforced mechanism of geotextile is analyzed. Specific reinforced effect is achieved by comparing data curve through experiment.
\end{abstract}

\section{Introduction}

Soft soil is distributed widely in our country, it is mainly composed of fine grain, and has the nature of high water content, low shearing stress and permeability, and bad compressibility. In actual project, if the soft soil program is not solved, such hazards as whole sliding abutment, damaged bridge abutment, large uneven settlement of structure and bank, water leakage in settlement joint, uneven settlement of roadbed will happen. Geotexile in soft soil engineering has an important role, mainly because it has such advantages as light weight, good continuity, construction convenient, high tensile strength, corrosion resistance and microbial corrosion, it has good combination with soil.

\section{Mechanism of reinforced soft soil by textile}

Reinforcement in soil, the reinforcement material is as tensile members, then restricting its upper and lower deformation of soil and enhancing shearing strength of soil. Reinforcing mechanism figure is shown as figure 1.

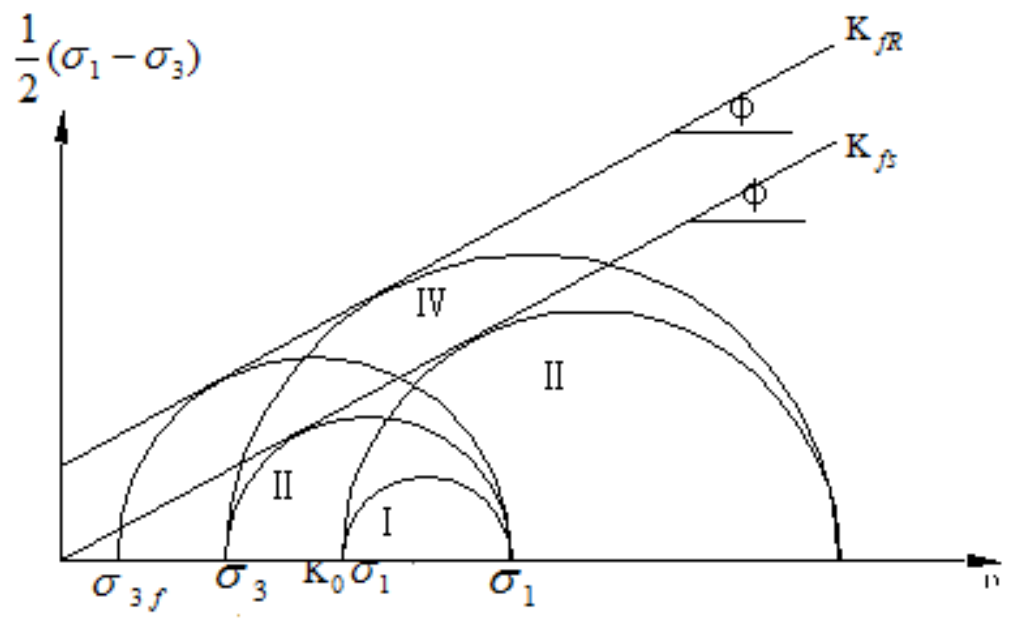

Figure 1 finite stress circle of reinforcement model

Initial stress of reinforced soil is $\sigma_{1}$ and $\sigma_{3}=k_{0} \sigma_{1}$. If $\sigma_{1}$ of soil and reinforced soil is unchanged, gradually reducing $\sigma_{3}$ to $\sigma_{3}=k_{a} \sigma_{1}$, the soil is in a state of ultimate equilibrium, and the strain is $\varepsilon_{a}$. The relationship between stress and strain can be considered as following: the strain is constrained to 
$\varepsilon_{R}$, reduced $\Delta \varepsilon=\varepsilon_{a}-\varepsilon_{R}$, making the reinforced soil is at a state of elasticity, enhancing the strength.

\section{Experimental study on geotextile and soil}

\section{Selection of soft soil}

The selection of soft soil should be based on the actual engineering. In the first, due to soil structure property and the actual needs of the project, the high standards can not be achieved, requiring further reinforcement measures, so when select the soil sample, the soil samples of optimum water content should be choosed to study. The optimal water content can be obtained primarily through the test data and the numerical fitting method combined application, shown as figure2.

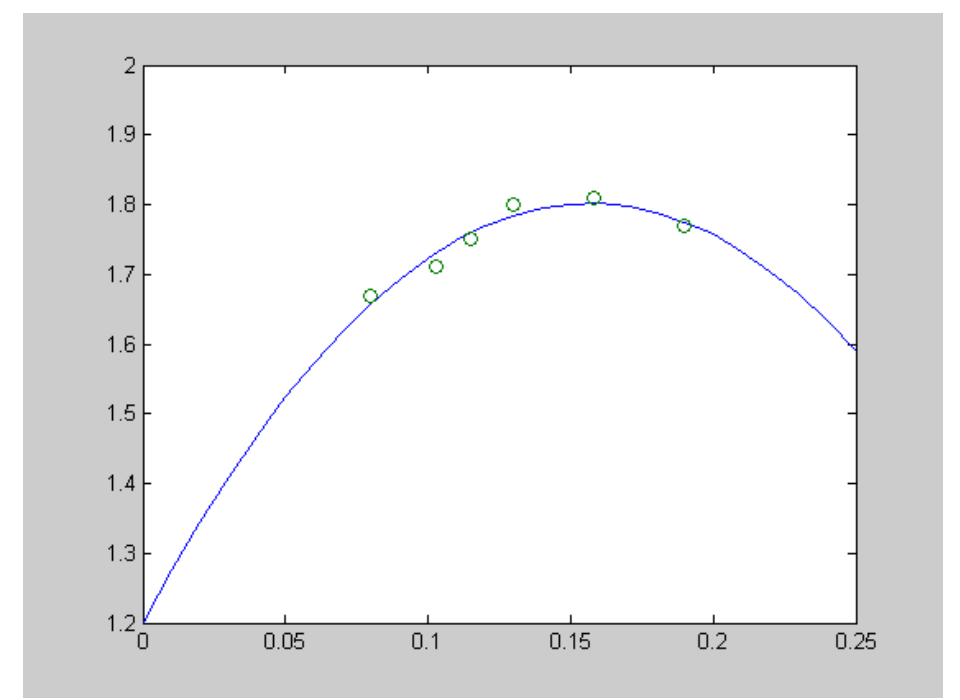

Figure2 the fitting curve of the best moisture

\section{Experiment of geotextile property}

The grip strength, tear strength, puncture strength and bursting strength of geotextile are tested by using geotextile test machine. When the geotextile properties have reached the need of design code, using it to reinforcement experiment.

\section{Research on reinforced effect by geotextile}

By experiment of soil, the optimum water content is $\omega=15.9 \%$, its corresponding maximum dry density is $\rho_{d}=1.815$. Samples of soil and reinforced soil are made. Uniaxial compression test is used to test above two samples, the compared result is shown as figure 3 and figure 4.

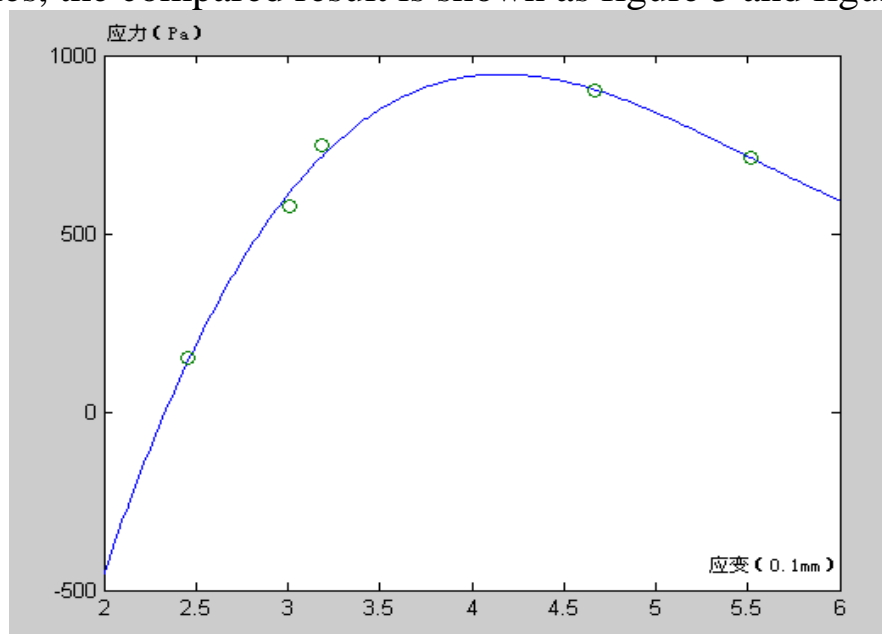

Figure 3 stress and strain of no geotextile 


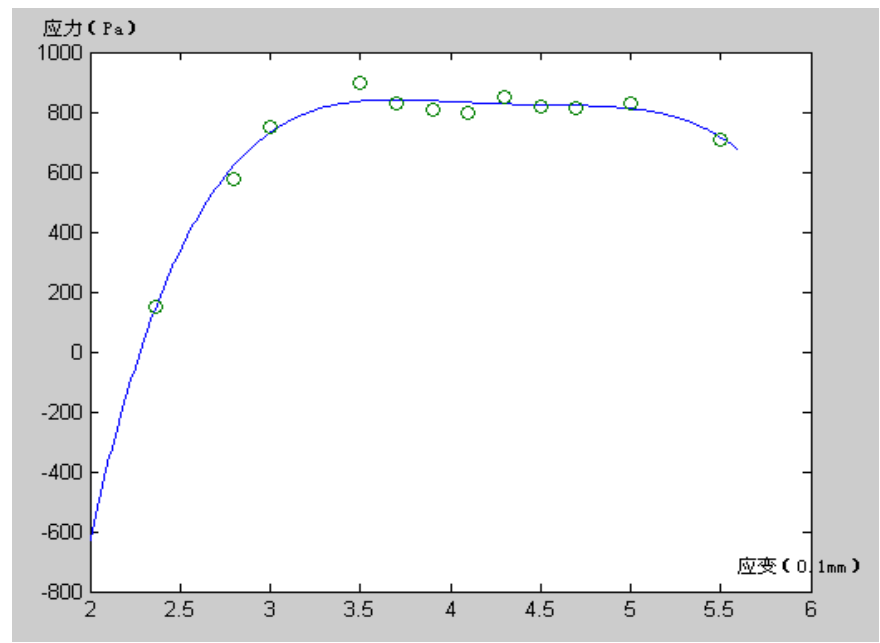

Figure 4 stress and strain with geotextile

Under the same experimental conditions, destructional forms of two samples are different. In the experiment of no reinforced soil, the destruction is along the shear destruction surface, because soil compressive strength depends entirely on the internal friction of soil. In that of reinforced soil, the destruction form of reinforced sample is breakage uniformly. Bearing capacity of soil with reinforced geotextile is bigger than that of no reinforced geotextile, because the geotextile enhances strength of soil. The entire block, plays a uniform stress effect, at the same time prevents shear failure to pass downwardly.

\section{Conclusions}

On the basis of previous study, mechanism, feasibility and reinforced effect of geotextile reinforcing soft soil are analyzed and discussed. Deformation and strength of reinforced soil are tested, some useful conclusions are achieved as following:

1) Water content of soft soil has great influence to its relative density. With soft soil water content decreasing, the relative density increases, but when the moisture content is reduced to a certain value, the moisture content decreasing, its relative density increases no longer, and begins to decrease, then the peak value point is the best water content, at the best water content, the soil compaction can achieve the best effect.

2) According to the geotechnical fabric mechanical properties test, maximum value of tensile strength, bursting strength, CBR punctured strength, trapezoidal tearing strength of geotextile appeared after a period of time, it is also the description of geotextile optimum mechanical properties play is in tension state occurred. Therefore, in practical engineering, geotextile must be paved, and tension, so as to achieve a good effect of reinforcement.

3) In soft soil reinforced and unreinforced comparative trials, from the test results that, as a result of geotextile reinforcement effect, greatly increasing the soil cohesion and internal friction angle, therefore, using geotextile tensile properties to enhance compressive and shear strength of soil.

\section{Acknowledgments}

This research was supported by Grants No. 11553061 from Education Department of Heilongjiang province and'research and practice of excellent engineer plan' from Education Department of Heilongjiang province.

\section{Reference}

[1] Qian Jiahuan, Yin Zongze. Principle and Calculation of Soil Engineering [M],Beijing: China Water Conservancy and Hydropower Press,2000 .

[2] Guo Jiwu, Feng Xiaochun, Guo yao. Soil and Foundation [M], Beijing:Tsinghua University 
press, 1996.

[3] Chang Shibiao, Manual of Engineering Geology [M], Beijing: China Building Industry Press ,1992.

[4] Luo Laifen, The Experimental Study on Dynamic Consolidation Combination with Vacuum Dewatering to Soft Foundation Improvement [D], China University of Geosciences, 2008.

[5] Cheng Pei-feng, Mu Wan-kui,Jiang Hai-yang. Finite Element Analysis of Shallow Soft Soil Foundation Reinforced by Geogrids [J], China Journal of Highway and Transport,2008(2).

[6] Xu Xinyue. Discussion on Prediction Method for the Settlement of Soft Soil Ground [J], Building Structure, 2003(03).

[7] Wang Jun,Chen Yunming. Analytical solution to 1-D consolidation of uniform structured soft foundation [J], Journal of Hydraulic Engineering,2003. 